\title{
Límites al poder de reforma, modificaciones y alteraciones a la Constitución*
}

\author{
Diego Mauricio Higuera Jiménez** \\ Recibido: junio de 2016 • Aprobado: junio de 2017 \\ DOI: 10.22395/ojum.v16n32a4
}

\begin{abstract}
RESUMEN
La Constitución Política de un Estado se puede definir como un acto jurídico político que establece la estructura del Estado, sus principios y fines esenciales, su modelo de Estado y de Gobierno, sus derechos constitucionales, deberes y mecanismos de defensa, entre otros, y se resume en la expresión Carta de navegación de dicho Estado. Si bien es cierto las constituciones son el texto jurídico de mayor relevancia en un sistema jurídico constitucional, las mismas deben adaptarse y ser dinámicas para responder a las necesidades del colectivo que rigen. Para ello, debe definirse el grado de rigidez en el procedimiento de reforma constitucional, que debe ser diferente al de una norma ordinaria. El presente documento estudiará las diferentes formas en que se puede reformar la Constitución Política en Colombia, tanto modificaciones formales como informales, y las alteraciones que dichas reformas o modificaciones producen en el ordenamiento jurídico, a partir del análisis tanto normativo como jurisprudencial, lo cual nos permitió establecer las diversas formas en que se puede alterar la carta original por una subsiguiente.
\end{abstract}

Palabras clave: Rigidez, seguridad jurídica, modificaciones, reformas, alteraciones, sustitución, quebrantamiento, destrucción de la Constitución.

\footnotetext{
Artículo de investigación científica y tecnológica, resultado del proyecto de investigación terminado "Los derechos como límites". Línea de investigación en Derechos Constitucional y fortalecimiento Democrático, enmarcado epistemológicamente en el análisis teórico deductivo.

** Abogado, Universidad Santo Tomas, Tunja. Magíster en Derecho Público y Ciencia Política, Université Nancy 2, Francia. Doctor en Derecho de la Universidad Externado de Colombia. Director del Doctorado en Derecho Público Usta-Tunja. Docente investigador del Grupo de Investigación Jurídicas y Socio-Jurídicas del CIS -Usta Tunja miembro de MENSA internacional. Correo electrónico: higuerajimenez.abogado@gmail.com
} 


\section{Limits to the power of reform, amendments and alterations to the Constitution}

\section{ABSTRACT}

The Political Constitution of a State can be defined as a political juridical act that establishes the structure of the State, its principles and essential purposes, its model of State and Government, its constitutional rights, duties and defense mechanisms, among others, and is summarized in the expression Navigation Chart of that State. Although constitutions are the most important legal text in a constitutional legal system, this should adapt themselves and be dynamic in order to respond to the needs of the collective that governs them. To this end, the degree of rigidity in the constitutional reform procedure must be defined, which must be different from that of an ordinary norm. This document will study the different ways how the Constitution can be reformed in Colombia, both formal and informal modifications, and the alterations that such reforms or modifications produce in the legal system, based on both normative and jurisprudential analysis, which allowed us to establish the various ways in which the original charter can be altered by a subsequent one.

Keywords: rigidity; legal security; modifications; reforms; constitution; alterations; formalisms; jurisprudence; legitimacy.

\section{Limites ao poder de reforma, modificações e alterações na Constituição}

\section{RESUMO}

A Constituição Política de um Estado pode ser definida como um ato jurídico-político que estabelece a estrutura do Estado, seus princípios e fins essenciais, seu modelo de Estado e de governo, seus direitos constitucionais, deveres e mecanismos de defesa, entre outros, e resume-se na expressão Carta Magna desse Estado. Embora seja certo que as constituições são o texto jurídico de maior relevância num sistema jurídico constitucional, estas devem ser adaptadas e ser dinâmicas para responder às necessidades do coletivo que regem. Para isso, deve-se definir o grau de rigidez no procedimento de reforma constitucional, que deve ser diferente do de uma norma ordinária. O presente documento estuda as diferentes formas em que se pode reformar a Constituição Política na Colômbia, tanto modificações formais quanto informais, e as alterações que essas reformas ou modificações produzem no ordenamento jurídico, a partir da análise normativa e jurisprudencial, a qual nos permitiu estabelecer as diversas formas em que a carta original pode ser alterada por uma subsequente.

Palavras-chave: alterações, destruição da Constituição, modificações, reformas, rigidez, segurança jurídica, substituição, violação. 


\section{INTRODUCCIÓN}

Este estudio tiene como objetivo establecer la manera en que se estructuran las diferentes formas de afectación a la Constitución, es decir, los alcances y efectos de las modificaciones a la Norma de Normas.

Si bien se acepta la idea según la cual las constituciones son fundamento de todo el sistema normativo y, por lo tanto, de ellas se desprenderá la totalidad del diseño institucional y garantista, es importante ver la dualidad existente entre la flexibilidad y la rigidez, en materia de la estabilidad de la Norma Normarum.

Esta dicotomía no es nueva, ya hace siglos Aristóteles sostenía "La razón nos dice que las leyes escritas no deben conservarse siempre inmutables. La política, y lo mismo pasa con las demás ciencias, no puede precisar todos los pormenores". Sin embargo, continúa diciendo "La innovación en las leyes es una cosa distinta de la innovación en las artes; la ley, para hacerse obedecer, no tiene otro poder que el del hábito, y el hábito sólo se forma con el tiempo y los años, de tal manera que sustituir ligeramente las leyes existentes con otras nuevas, es debilitar la fuerza misma de la ley" (Aristóteles, 2006, p. 31).

La rigidez, es decir, que la Constitución posea mecanismos de reforma agravados, es un elemento natural del poder jurídico superior; así se velará por la muy necesaria estabilidad que mantiene su supremacía jerárquica sobre las demás normas. Por supuesto, esto no impide que la Lex Legum pueda ser reformada, pues la misma debe tener igualmente un componente de flexibilidad, lo cual permite su adaptación a las nuevas circunstancias y exigencias mediante reformas que pueden ser innovadoras, actualizadoras, explicativas, correctivas; pueden enfocarse a adecuar, a ampliar y a desarrollar la Constitución, a hacerla más efectiva, garantista y conveniente, a evitar la tentativa de derogación de ella; después de todo, es más fácil hacer un ajuste que permita canalizar las exigencias y necesidades políticas, que revocar la Norma Suprema (De Vega, 2007).

Una reforma formal y explícita de la Constitución, que respete los procedimientos establecidos y las competencias asignadas al órgano de reforma, es, en principio, una modificación legítima y jurídica. Sin embargo, en ocasiones se utilizan mecanismos formales para alterar de manera sustancial y anti-técnica la Lex Legum, mediante modificaciones impulsadas por intereses particulares, regresivos o contrarios al Estado social de derecho, desnaturalizando la Constitución e incluso destruyéndola, defraudando la competencia que tiene el órgano de reforma, por tratarse la misma de un poder constituyente-constituido. Con ocasión de esta diferencia entre reformar y alterar, no son pocas las vías (formales e informales) que afectan de esta última forma la estabilidad de la Constitución; sin embargo, existe confusión respecto a cómo las mismas se sobreponen y los efectos jurídicos de una u otra categoría.

El respeto de estos límites, implica defraudar o no los procesos institucionales, por lo tanto, se trata de un lado, de ejercer una auténtica democracia republicana o por el contrario, que la misma sea coop- 
tada por agentes que la manipulen. La idea no es nueva, pues la misma puede apreciarse en Aristóteles en su obra La Política, cuando nos habla de las especies diversas de democracia, diferenciando entre la democracia legal y la democracia no legal. En la primera, existe la idea de limitación del poder popular con respecto a los llamados Nomoi, es decir, normas abstractas en las cuales se cimienta la vida de la comunidad, pudiendo solo definirse aspectos propios de las llamadas normas Psefismataque por su rango inferior pueden ser sujeto de decisión votada (Aristóteles, 2006)

Por supuesto, la democracia es ejercicio del poder popular, pero este no puede, por mayoría, decidir cualquier asunto de cualquier forma; límites como los derechos humanos o la dignidad humana no radican únicamente en la soberanía del número. Así, cuando "la decisión popular, no la ley, lo resuelve todo. Esto es debido a la influencia de los demagogos" (Aristóteles, 2006, p. 85).

En el fondo se trata de la diferencia entre democracia real y demagogia, que bien reseña el profesor Gonzalo Ramírez (2008), atenta contra los elementos definitorios de la sociedad misma al modificar sus Nomoi; y más que un acto democrático, es una usurpación por parte de la demagogia. Después de todo, "Los demagogos, para sustituir la soberanía de los derechos populares a la de las leyes, someten todos los negocios al pueblo porque su propio poder no puede menos de sacar provecho de la soberanía del pueblo de quien ellos soberanamente disponen, gracias a la confianza que saben inspirarle". (Aristóteles, 2006, p. 85)
Esto nos recuerda la evolución ocurrida en la famosa fábula, Rebelión en la granja, de George Orwell: esa revolución animal en la que los cerdos, con el apoyo de las demás bestias de la finca, toman el control para detener la explotación de la que son víctimas fue, en su oportunidad, coronada con una gran declaración de derechos animales.

Todo lo que camina sobre dos pies es un enemigo.

Todo lo que camina sobre cuatro patas, o tenga alas, es un amigo.

Ningún animal usará ropa.

Ningún animal dormirá en una cama.

Ningún animal beberá alcohol.

Ningún animal matará a otro animal.

Todos los animales son iguales.

Con el tiempo se hicieron reformas.

Casi todo lo que camina sobre dos pies es un enemigo

Ningún animal dormirá en una cama con sábanas.

Ningún animal beberá alcohol en exceso.

Ningún animal matará a otro animal sin motivo. Todos los animales son iguales, pero unos más iguales que otros.

Es evidente, que en este caso la voluntad originaria y sus valores han sido defraudados.

Así las cosas, para establecer cómo son valoradas desde una perspectiva jurídica las diferentes alteraciones a la Constitución, cuando convergen o no las mismas, su concepto y alcances, se ha desarrollado este escrito. En una primera parte se 
analizará (1) La naturaleza de la reforma, por lo tanto, el principio de rigidez y la tensión de la judicialización de los actos reformatorios de la Constitución; con posterioridad se introducirá al lector a estudiar las diversas (2) Alteraciones constitucionales, en ellas se evidenciará la reforma constitucional tácita, la sustitución, la modificación tácita directa y la indirecta, el quebrantamiento, la suspensión, la mutación, la elusión de la Constitución y las costumbres constitucionales.

\section{METODOLOGÍA}

El proceso científico implica el abordaje del objeto, el método y el fin (SCARCIGLIA, 2006), Nuestro objeto de estudio inicia por la reforma constitucional (principio de flexibilidad) y sus límites como procedimientos normativos (principio de rigidez), para posteriormente abordar el fenómeno del cambio en la Constitución, es decir, la modificación de la misma, lo que nos lleva a estudiar cuándo la modificación, es decir, cualquier cambio, no solo los propios del poder de reforma, entraña un acto válido y cuando no, es decir, cuando la misma ha derivado en una alteración a la Carta Magna.

Para este trabajo utilizaremos una metodología con esquemas de teoría de grupos, que se nutre de la configuración de categorías producto de la hermenéutica, la cual se centra en un procedimiento analítico-conceptual de orden deductivo. Para ello, se toman como premisas las concepciones normativo-teóricas de las fuentes seleccionadas con miras a deducir los elementos relevantes desde las pers- pectivas epistemológicas que respondan a nuestra pregunta de investigación.

Los esquemas en teoría de grupos nos permiten sistematizar de manera analítica los conceptos y así superar una etapa actual de la caracterización en las alteraciones, pues no solo las enumeramos y explicamos, sino que evidenciamos la relación concurrente y excluyente entre ellas.

Como finalidad del estudio se pretende determinar: ¿Cuáles son los efectos jurídicos de las diversas formas de afectación a la estabilidad de la Constitución como norma rígida?

\section{RESULTADOS Y DISCUSIÓN}

\section{LA REFORMA A LA CONSTITUCIÓN Y SUS LÍMITES}

La reforma a la Constitución permite mejorar las garantías, ajustar las instituciones, corregir imprecisiones que se evidencian sólo en la práctica, actualizar las normas a la realidad social, responder a las reclamaciones sociales y a las presiones políticas; es, por lo tanto, adaptación y supervivencia de los mandatos superiores, pero este poder debe estar sometido a determinados límites, los cuales imponen diversas obligaciones al principio de flexibilidad, garantizando, mediante la rigidez, la estabilidad y supremacía de la Carta Magna.

\subsection{La naturaleza de la reforma, la dualidad entre la rigidez y le flexibilidad}

En la actualidad las constituciones versan sobre asuntos en torno de temas socia- 
les, políticos y económicos ${ }^{1}$.La creación de una Constitución tiene como objetivo específico establecer ciertos límites y pautas de acción entre los distintos poderes del Estado, es decir, reglamenta la relación entre lo legislativo, lo judicial y lo ejecutivo, además, constituye los derechos que el pueblo que conforma el Estado y establecer, a partir de ella, los fundamentos generales para el gobierno de una determinada nación.

Las constituciones han sido entendidas como el acto jurídico-político por medio del cual las naciones se dotan de instituciones permanentes con lo cual se establece una división de poderes que enmarca las competencias y los procedimientos propios de las generaciones de normas, a la vez que en ellas mismas se plasma el contenido de garantías y derechos fundamentales que habrán de ser respetados y desarrollados en la sociedad (Tobo, 2006).

Los Estados constitucionales se cimientan en dos grandes principios: el políticodemocrático, de un lado, y el jurídico-normativo, de otro; en el primero se respeta el origen derivado de la soberanía popular de la Carta Magna, y en el segundo, la supremacía que es propia de la misma Ley Fundamental, para así dar cabida a la naturaleza propia del acto constitucional como norma de orden jurídico-político; por lo tanto, en las constituciones mismas existe todo el tiempo la tensión entre las manifestaciones del principio democrá-

Por supuesto, sin ser exclusivo o excluyente, pues las relaciones morales y los usos convencionales se positivizan en la Lex Legum. tico y el respeto debido al principio de supremacía constitucional.

Por supuesto, el pueblo como conglomerado es el soberano. Esta soberanía es inalienable, intrasmisible y, a decir de Rousseau (1990), infalible²; este soberano que no reconoce poder superior alguno es el único detentador legítimo de las decisiones colectivas; claro, esto ocurrirá solo cuando actúe en calidad de soberano ejerciendo la competencia del constituyente originario, pero, además, en las sociedades contemporáneas este pueblo soberano no actúa por sí mismo, sino que en la gran mayoría de ocasiones se manifiesta a través de órganos delegados. Esa democracia representativa, adhesiva a decir de nuestra Constitución, se encuentra así frente la idea según la cual la Ley de Leyes tiene una naturaleza limitadora y realizadora de los poderes públicos por lo que deberá, como norma de normas, limitar el ejercicio del poder a su marco normativo. Esta postura se justifica, ya no en la soberanía popular sino en la división misma entre gobernantes y gobernados.

Una vez elegidos los representantes de la forma de gobierno democrática, aparecen una ruptura y una división entre quienes poseen las decisiones de la colectividad y quienes no; si bien todos son parte del soberano parece que no todos tienen la

2 Nos referimos a la soberanía interna en cabeza del constituyente primario, es decir el pueblo -nación, pues a nivel internacional la soberanía es relativa, el Estado no es un superior sino un igual, con competencias matizadas por delegación, como ocurre con las normas de orden europeo o con las normas del bloque de constitucionalidad en Colombia. 
misma capacidad de decisión dentro de la ejecución misma de las ramas del poder público. Así la Constitución buscará limitar el ejercicio de estos órganos delegados para que ellos mismos se mantengan sometidos a la materialización del pueblo soberano en calidad de constituyente primario.

Así pareciera ser que se encuentra ante un patético dilema, a juicio de De Vega "Como solución a este patético dilema $y$, en definitiva, como punto de confluencia y lugar de encuentro de toda la problemática que suscita el antagonismo entre los supuestos políticos y jurídicos en que descansa el Estado constitucional, de la que innecesario resulta ponderar su significación e importancia" (2007, p. 21.), pues en la Constitución confluyen aspectos jurídicos y aspectos políticos, cuya tensión se materializará con notoriedad en el poder de reforma. Esta Constitución puede prever en ella misma su mecanismo de transformación y cambio para que solo bajo sus presupuestos se creen normas de carácter supremo, con lo cual se mantiene así un equilibrio y una apertura a la respuesta de las necesidades sociales contemporáneas. Después de todo reformar la Carta Magna es un acto de equilibrio y modificación pacífica de las realidades sociales.

Más allá de las diversas formas como, amendment (USA), revisión (Francia révision o Italia revisione), o reforma (Colombia), el cambio permite empalmar los aspectos políticos y los aspectos jurídicos, pues la reforma constitucional es una verdadera regla de cambio, porque faculta a introducir nuevas reglas en el sistema y en el mismo nivel (Ferreyra, 2007), lo que gene- ra que la Carta Magna responda a las exigencias y circunstancias de la sociedad, sin desestimar el principio de rigidez por el cual una Constitución debe ser difícil de modificar, pues si no existe un mecanismo agravado para su reforma la misma pierde su principal característica, la supremacía; entiéndase que una norma es tan fuerte normativamente como las exigencias para hacerse: si se modifica igual que una ley, esta será su auténtica jerarquía.

Si la Constitución es modificada por cualquier vía esta pierde la misma naturaleza pragmática de superior, mientras que si se hace inmodificable pierde su potencial de regulación de la vida social; así, no cualquier reforma responde ante esta exigencia sino de manera exclusiva aquella a través del procedimiento agravado que pretende volver a solucionar esta tensión existente en el Estado constitucional, por lo cual se responderá a las exigencias propias de la política respaldadas o materializadas por el principio democrático sin vulnerar los requerimientos jurídicos propios de la supremacía constitucional.

Así la Constitución podrá seguir existiendo en el tiempo, mientras responda a las circunstancias y requerimientos sociales. Esta dialéctica entre lo positivo descrito y lo realizado en la materia de lo social evidencia la relación dinámica entre la norma y la sociedad; la simple realidad no construye derecho y la norma sin conexión con la realidad no es una materialización jurídica; por eso la naturaleza de la reforma vendrá a ser una muestra de la teoría constitucional en sí misma. 
Por supuesto, cada ordenamiento tiene diferentes niveles de rigidez y flexibilidad al momento de establecer los mecanismos y límites de las reformas constitucionales, propias de la credibilidad de (y en) sus instituciones, su dinámica política, su respeto por la Norma Suprema, y estabilidad política.

En respeto de la rigidez, la reforma deberá desarrollarse dentro de determinadas reglas, por lo que se deberá estar muy atentos a la forma concreta en la que ha de hacerse, en todo caso, el que esta modificación deba hacerse sometida a las reglas de la Constitución, para que la misma no pierda su naturaleza. Se tendrá que encontrar en la actuación de un poder constituido, lo que es lo mismo, solo hay reforma a la Constitución dentro de los poderes constituyentes constituidos, lo que centra la distinción entre poder constituyente originario en cabeza del soberano y poder constituyente delegado o constituido, el cual es un órgano de competencia limitadas y no soberanas ${ }^{3}$.

Por lo tanto, no existen poderes constituidos supra o extra constitucionales; solo el soberano organizado en calidad de tal tendrá esta facultad de reforma como órgano constituyente originario, no así los órganos creados por la Constitución misma; dicho de manera explícita y con firmeza, se sostiene que los órganos

3 No existe poder otorgado por la Constitución para actuar contra la Constitución misma. Bien se expresa Sieyès (2008) "Ningún tipo de poder delegado puede cambiar lo más minimo de las condiciones de su delegación. Las leyes constitucionales son, en este sentido, "fundamentales". constituidos no pueden realizar un acto en contra o por fuera de la Constitución.

\subsection{Tensión juridico-politica y judicialización de los actos reformatorios de la Constitución}

Una Constitución es planteada como un acto de naturaleza jurídica y política, pues en ella convergen los fundamentos de la soberanía popular, por lo que se despliega a través del principio democrático a la vez es la Norma de Normas la de suprema jerarquía en el ordenamiento jurídico. No en vano esta dualidad de la Carta Magna viene a ser un elemento central del estudio de la misma, pues si dicha norma permanece inmutable en el tiempo pierde capacidad para regular la vida social, por lo tanto se volvería en un simple acto declaratorio de postulados abstractos y pretensiones políticas, se desfiguraría en este orden de ideas su capacidad de reglar normativa y por lo tanto en una forma coercitiva la vida social. Si existe un divorcio entre la norma suprema y la vida social, la primera terminará por perder su capacidad de eficacia, sin embargo si ésta se modifica con relativa frecuencia, pierde su credibilidad en tanto que es norma fundamental del Estado.

Asimismo, si se modifica por un órgano que también tiene la competencia legislativa se desnaturalizaría su fuerza de superioridad jerárquica, pues nada nos permitiría distinguir una norma de orden legal de una norma de orden constitucional; esta tensión viene a acrecentarse cuando resalta la evidencia social e histórica en la que el detentador de ese poder de reforma abarque para sí esos 
poderes, abrogándose la soberanía del constituyente primario a través de su competencia como órgano constituido titular del procedimiento de reforma.

En este orden de ideas habrá que insistir que el poder de reforma siempre es un acto constituido, y no puede ser utilizado para destruir la Constitución misma; esta reforma posee varias funciones: permite mantener la conexión necesaria entre la realidad jurídica y la realidad política, a la vez que evita la destrucción misma de la Carta, lo cual mantiene una solución de continuidad en la misma, lo que hace que, en consecuencia, sea una garantía única de estabilidad de ella; por supuesto, esta característica propia del poder de reforma sólo tiene sentido dentro de la construcción de las constituciones rígidas, creando así una barrera frente a la debilidad que vendría de enfrentarse a mayorías más o menos coyunturales.

No quiere decir que la Norma Normarum deba ser sometida a procedimientos engorrosos para su reforma, ni que no pueda ser derogada, al punto que la cláusula de reforma se entiende implícita dentro de la carta constitucional ${ }^{4}$; lo que se insiste en este orden de ideas es en la necesidad de llamar a cada acto por su nombre y por tanto si se trata de un acto reformatorio de un órgano constituido, no debe este destruir el marco constitucional; en cam-

4 De manera común se entiende que los elementos esenciales de la Constitución son la parte dogmática y la parte orgánica, mientras la cláusula de reforma, la tutela judicial efectiva y la interpretación pro homine son elementos naturales de la misma, es decir se entienden incluidos a pesar de no estar explícitos (Higuera, 2015-B). bio, si lo que pretende es la revocatoria de la vigente para plantear una nueva, se trata de un acto constitucional supremo de naturaleza fundacional de una nueva Constitución en cabeza del poder constituyente originario, para lo cual será indispensable decirlo en estos términos, para que la voluntad soberana que se materialice se haga de forma consciente al respecto, libre de error, fuerza o dolo. Después de todo no se puede decir que se encuentra dentro de los preceptos de algo para destruir esto mismo; de ahí que se consideren antijurídicas las alteraciones como el fraude a la constitución, el quebrantamiento, la suspensión o la sustitución.

La situación se vuelve interesante en nuestro sistema jurídico, pues se trata de una Constitución, en parte, rígida a punto que la doctrina extranjera, tal como Ferreyra (2007), quien la define de esa manera, así tanto por tratarse la rigidez constitucional de un mandato normativo superior, como por las dificultades propias de la dinámica política y jurídica colombiana, en falta de representatividad, legitimidad, se evidencia la necesidad de complementar esta institución en sede jurisprudencial.

Entender la problemática de la reforma de otra manera nos implicaría someter la norma suprema, como materialización de los preceptos soberanos de la totalidad del pueblo, a una mayoría coyuntural de orden político y partidario, pero, también una extrema rigidez nos alejará de la necesidad de dinamismo supremo, para adaptarnos e incluirnos en la realidades 
sociales; por lo tanto, es necesario estar atentos a la naturaleza concreta del acto para exigir mayores o menores presiones, pues mientras más participación haya, más propio de la naturaleza influyente de la Constitución será el acto, por otro lado, no podrá pensarse lo mismo cuando se trate de un solo órgano el que de manera unilateral tome una decisión.

Siempre se planteará una reforma constitucional como una urgencia y un acto de carácter indispensable para la vida pública de una nación; así se impondrá la necesidad propia de esa modificación, pero estas situaciones cuando se presentan de manera reiterada, implican el resquebrajamiento de la confianza en la inviolabilidad de la Constitución y por lo tanto una pérdida de su propia fuerza normativa, como bien lo plantea Hesse (2011), así la conveniencia política de una norma debe siempre ser leída en clave de su plausibilidad y necesidad jurídica.

Las constituciones son normas de carácter amplio y, por lo tanto, en ellas, como espacios de consenso, caben múltiples interpretaciones y regulaciones. Una modificación de la Constitución es una cirugía delicada dentro del cuerpo político y no puede ser un simple reacomodo de las reglas del juego por una mayoría coyuntural, si bien debe insistirse en que el no acudir al procedimiento de la reforma, cuando exista exigencia histórica y social, no aportará a esa estabilidad de la Constitución, al contrario, la debilitará por hacerla más ineficaz y lejana de la sociedad.
Así la pertinencia, la juridicidad y la legitimidad política a una reforma deben ser analizadas detenida y detalladamente en un caso concreto, por lo que aumentan su relevancia los criterios interpretativos y argumentativos que han venido siendo objeto de estudio.

Por supuesto, la falta de exigencias argumentativas y la misma naturaleza de representatividad subjetiva en los espacios legislativos alejan la pretensión de objetividad y racionalidad del discurso; los llamados desajustes de la democracia nos llevan a pensar en una invitación a mayores exigencias argumentativas, expositivas y racionales por parte de los operadores legislativos y no en una razón para la inexistencia de control sobre las normas de reforma; después de todo, cuando actúan como poder de reforma se encuentran en una función diferente e incluso más exigente a aquella en calidad de órgano legislativo, y deberá tener una mayor carga argumentativa en él, tanto en aspectos fácticos, como normativos e interpretativos de sus decisiones.

Cuando esto no suceda habrá más campo a la discrecionalidad judicial, la que también debe ser desterrada del ordenamiento jurídico, pues solo una decisión respetuosa de los criterios lógicos, materiales, dialécticos e interpretativos del conglomerado normativo nos permitirá mantener vigente la soberanía popular y no una oscilación de tensiones entre unas u otras mayorías.

A continuación puede verse un esquema sobre las diferentes formas de límites al poder de reforma. 


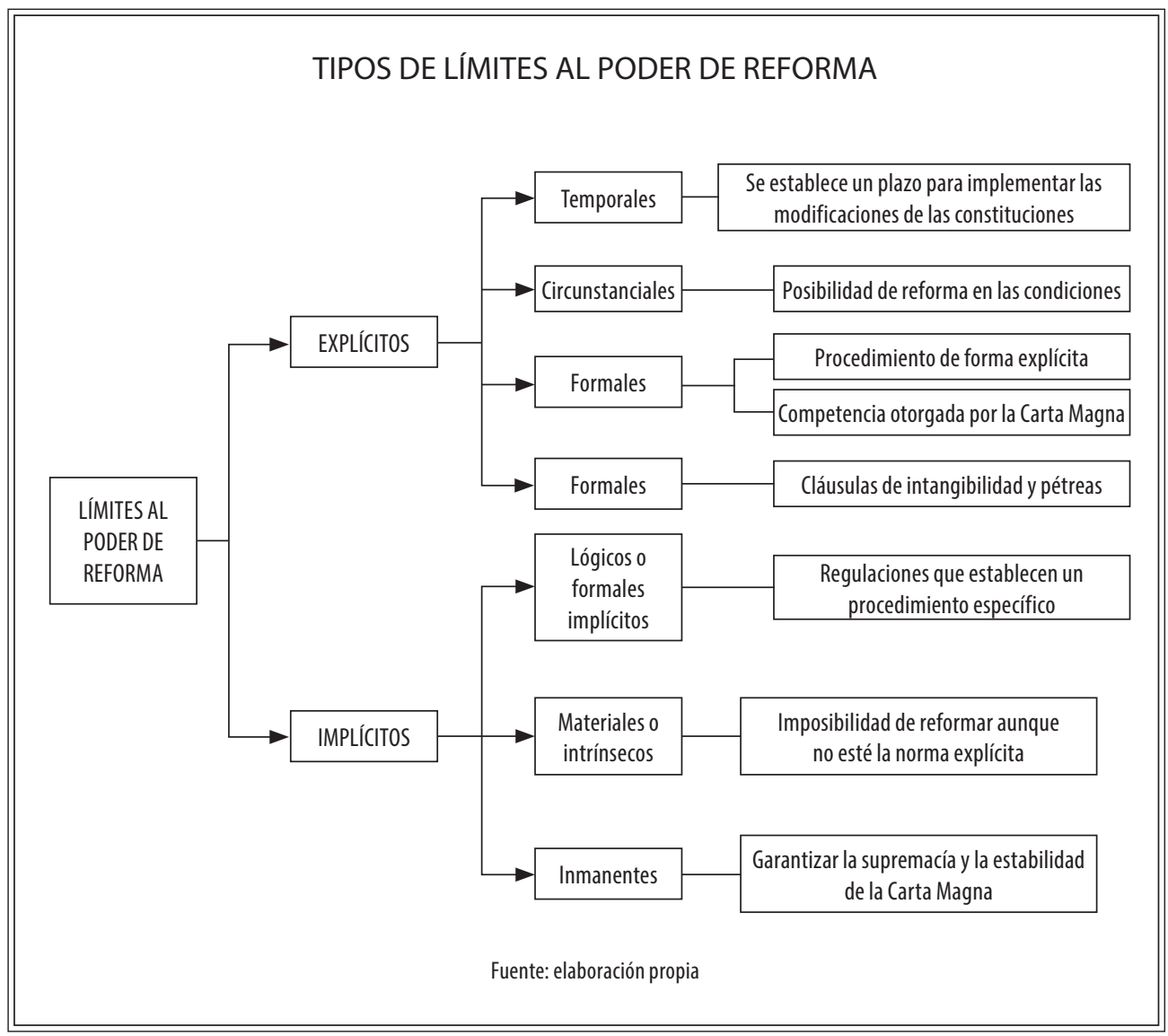

\section{MODIFICACIONES Y ALTERACIONES A LA CONSTITUCION}

A continuación, se hablará de algunas modificaciones a la Carta Política que son contrarias al sistema jurídico y que entrañan alteraciones a la Constitución. Por supuesto, no incluiremos modificaciones que sean realizadas por un proceso válido de reforma.

Se ha escogido el término alteración para distinguirlo del de reforma o modificación, pues los cambios que se refieren a continuación incluyen actos que deben ser considerados como antijurídicos y excluidos del sistema de derecho. Consideramos, por lo tanto, la reforma como la consecuencia de competencia de un órgano constituido, y en este sentido el acto jurídico de cambio en la norma superior; la modificación por su parte es un hecho (el cambio en sí) que puede darse por el poder de reforma o por fenómenos político-sociales; finalmente la alteración será una consecuencia de determinadas modificaciones, siendo excluyente con la idea de reforma. 


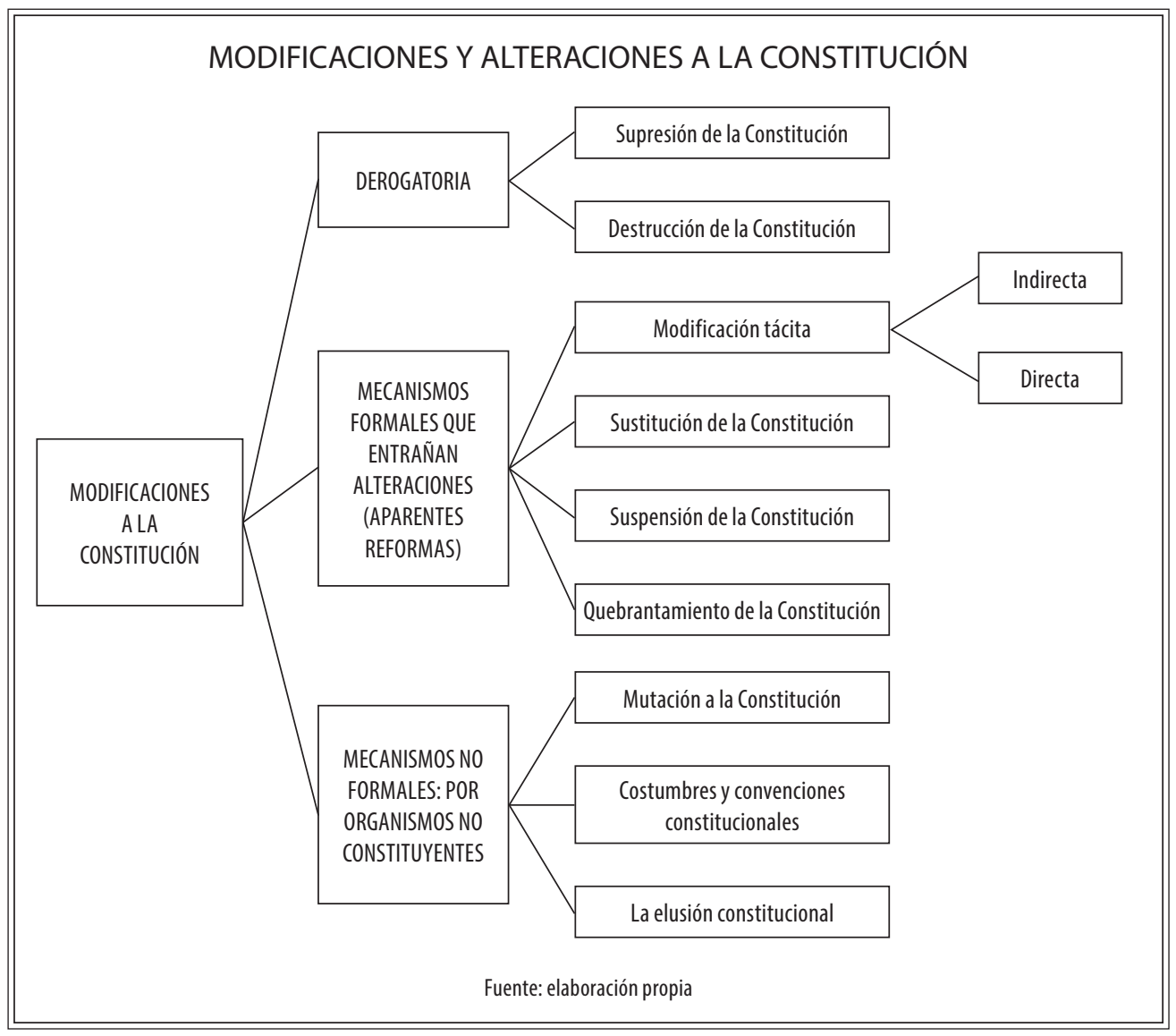

Dado que las tres grandes formas de alteraciones a la Constitución poseen características diferentes no pueden agruparse en un solo esquema de conjuntos, por lo cual cada una será organizada respectivamente, en un cuadro en razón a la modificación que le da origen.

\subsection{Derogatoria de la Constitución}

Los compendios normativos de orden constitucional poseen múltiples mecanismos para mantener la pertinencia y conexión de la normativa con la realidad social, pues, citando a Ferreyra "La disposición normativa que regula la reforma constitucional tiene una peculiaridad: garantiza la continuidad de la regla democrática" (2007, p. 371.), de conformidad con lo pertinentemente definido en el sistema de derecho, siendo conocidos en nuestros ordenamientos los mecanismos de reforma y derogatoria constitucional.

En realidad no existe positivamente el término derogatoria constitucional ${ }^{5}$, pues el mismo abarca la existencia de un órgano con competencia para proferir, dentro del

5 Mantendremos el mismo, dada la claridad que ofrece al entendimiento común. 
sistema de derecho, una norma nueva de orden constitucional, cuando en realidad en el poder constituyente primario es supra normativo pues "cada parte de la Constitución no es obra del poder constituido, sino del poder constituyente". (Sieyés, 1987, p. 86).

En la reforma, se modifica un aspecto de la Constitución, pero su compendio y su vida como cuerpo permanecen; en el segundo, es decir en la derogatoria, se da nacimiento a un nuevo ente de disposiciones fundamentales las que permitirán dar un nuevo desarrollo a las circunstancias sociales.

Utilizamos esta terminología para la derogatoria de la Lex Legum, indistintamente del acto político concreto que dé lugar al mismo, es decir, revolución, separación, independencia, golpe de Estado, restauración, etc.

\subsubsection{Supresión de la Constitución}

En el caso de la supresión de la Constitución se conserva el poder constituyente en que la misma se basa, pero es desprovista de valor jurídico; puede ser el caso francés en el cambio de 1948 a la Constitución de la V República de 1958, al cambiarse una Carta por otra, sin negar el poder constituyente ${ }^{6}$.

$6 \quad$ Otro ejemplo útil se evidencia en el cambio de las Cartas de 1863 a la del 1886, parece ser que el reconocimiento de la soberanía popular es meramente retórico en vigencia de la Constitución de 1886, lo que es claro es que ésta última constituía un enfrentamiento a la Carta de 1863, en relación con su rigidez y reconocimiento de derechos, y que con la misma se amplió la brecha entre gobernantes y gobernados. "Después de expedida la Preconstitución y casi anticonstitución de 1886" (Angulo Bosa, 2002).
En las situaciones o casos en que se presentan supresiones a la Constitución son revaluadas las decisiones políticas fundamentales que estructuran la Constitución material "y no pertenecen a la competencia de las instancias autorizadas para reformar y revisar las leyes constitucionales. Aquellas reformas dan lugar a un cambio de Constitución, no a una revisión constitucional" (Schmitt, C. 1982 P. 120).

Por lo tanto, el poder de revisión posee un límite inherente a sus funciones en la proscripción de supresión, lo cual se evidencia cuando existen prohibiciones de reforma, pero es igualmente aplicable en ausencia de cláusulas pétreas: "incluso cuando se habla de una revisión total de la Constitución hay que observar la distinción antes expuesta, y atenerse a los limites de la facultad de revisar que de ella resulta" (Schmitt, C. 1982, P. 121).

Si se observa, podemos concluir que la sustitución de la Constitución ${ }^{7}$ puede ser una forma calificada de la supresión de la Carta Política al verse en concreto la causa iuris que permitió tales declaratorias en los casos de los fallos C-588 de 2009 y C-141 de 2010, proferidos por la Corte Constitucional colombiana, conforme los cuales bajo la apariencia de la utilización de un mecanismo de reforma, y sin negar el poder constituyente primario en el pueblo, se modifica la Carta Magna de tal manera que no se podría seguir concibiendo como la misma.

Si bien la supresión y la sustitución no son excluyentes, no son conceptos ne-

Cuando se realiza por un órgano constituido y mantiene el poder constituyente. 
cesariamente concurrentes. No toda supresión de la Constitución es una sustitución, pues aquella podría darse por golpe de estado o, incluso, convocatoria a asamblea constituyente en desarrollo de los procesos institucionales, solo lo será la dada por la utilización de mecanismos de reforma que no nieguen el poder constituyente, particularmente en las sustituciones parciales e incluso la sustitución válida constitucionalmente a través de Asamblea Nacional Constituyente $^{8}$.

\subsubsection{Destrucción de la Constitución}

En la destrucción de la Constitución se suprime la Carta Magna, a la vez que se suprime el poder constituyente en que la misma se ha soportado, siendo ante todo una negación de un anterior poder constituyente; es por lo tanto, una auténtica ruptura política nacional y evidentemente una actuación extrajurídica que puede ser o no de orden fundacional, por lo que en caso en que se opte por proferir una nueva norma superior, actúa claramente como nuevo constituyente.

Dadas las características de la destrucción de la Constitución es claro que la misma ha de distinguirse de la reforma en desarrollo de los poderes constituidos; así afirma Schmitt; "los órganos competentes para acordar una ley de reforma de la Constitución no se convierten en titular o sujeto del poder constituyente. Tampoco están comisionados

8 Recordemos que la asamblea en uso del artículo 376 puede ser constitucional o constituyente, en el primer caso se tratara de un órgano constituido y por lo tanto sujeto a los limites competenciales. para el ejercicio de éste poder constituyente, por tanto, no son una especie de Asamblea Nacional Constituyente con dictadura soberana, que siempre subsiste en estado de latencia" (Schmitt, 1982, p. 115).

La supresión de la Carta vigente junto con la negación del poder constituyente en que se basa (la destrucción) puede ocurrir por una usurpación del poder de reforma, pues "una reforma de la Constitución que transforme un Estado basado en el principio monárquico en uno dominado por el poder constituyente del pueblo, no es en ningún caso constitucional" (Schmitt, 1982, p. 120).

Lo mismo valdrá decir de un cambio democrático a uno monárquico, el cual solo se alcanzaría mediante la destrucción de la Constitución. La renuncia de una de las partes no sería más que la renuncia a la lucha, pero no la configuración de un nuevo poder constituyente; después de todo, la destrucción de la Constitución incluye la supresión del poder constituyente en que se basa.

Por ello, si mediante una modificación (sea o no vía reforma) se eliminara la soberanía popular, en el caso colombiano, si se tratara de una modificación por acto de reforma ese acto sería una inconstitucionalidad por sustitución concurrente con la destrucción de la Norma Normarum.

Para una mejor ilustración, se presenta el siguiente cuadro en el que se evidencia la interrelación de los conceptos entorno a la derogatoria de la Constitución: 
Destrucción y supresión respecto de la sustitución de la constitución

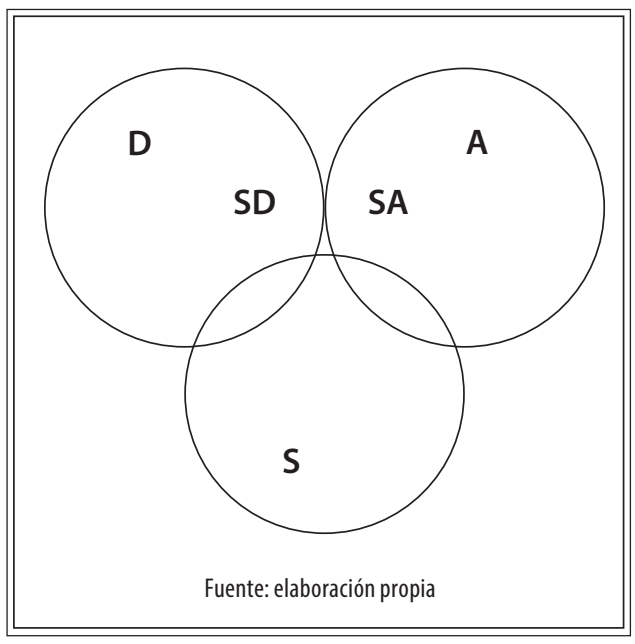

S: Sustitución de la Constitución, afectación grave en un elemento definitorio de la Carta Magna.

D: Destrucción de la Constitución, implica la eliminación de la Carta y el desconocimiento del poder constituyente.

A: Supresión constitucional, donde la norma suprema es eliminada, aunque se mantiene el reconocimiento del poder constituyente.

SD: La eliminación por la apariencia de reforma de un elemento esencial de la Carta que implica la eliminación del poder constituyente.

SA: Se elimina por la apariencia de reforma un elemento esencial de la norma suprema a través de un mecanismo formal de reforma, lo que conserva el poder constituyente.

\subsection{Alteraciones por modificaciones formales}

Las modificaciones formales están desarrolladas en los mecanismos establecidos por el constituyente primario para ejercer el poder de reforma, es decir, la revisión explícita, en la reforma tácita desarrollada por mecanismos formales no se ejercen poderes en consonancia con lo previsto en la Carta misma. Estos son los casos de sustitución, ruptura, quebrantamiento, y suspensión constitucional, las cuales se explican a continuación.

Los mecanismos no formales implicarán reformas a la Carta Magna a través de las fenómenos no reconocidos en la Norma Suprema; son los casos de la mutación, el fraude y la elusión constitucional, que se erigen como tal, y a través de cualquiera de estos múltiples mecanismos de alteración puede llegarse a la consecuencia objeto de nuestro estudio de la sustitución a la Constitución, caso en el cual la Carta Magna, como integralidad, verá desnaturalizados sus elementos definitorios y no podrá hablarse de la permanencia de la misma sino de una nueva Norma Normarum ${ }^{9}$.

En cuanto a los mecanismos formales, no se refieren al acto fundacional del poder constituyente como categoría propia de la soberanía popular y de la autoridad política; así las cosas bástenos con decir que al ser un acto fundacional, político y soberano escapa a los poderes jurídicos, y no puede ser una medida sujeta de control, como lo ha expuesto la Corte Suprema de Justicia en su sentencia del nueve de octubre de 1990, que avala el proceso constituyente de la Carta del 91. Por su parte respecto de las aparentes

9 Si bien se habla de sustitución por vicios de competencia en ejercicio de los poderes de reforma formales, no evita que en estos mecanismos de manera indirecta sustituyan la Constitución misma. 
reformas que entrañan una alteración a la Constitución habrá que referirse en los espacios subsiguientes.

\subsubsection{La reforma constitucional formal tácita, directa e indirecta}

Como mecanismo formal de modificación de la Carta se encuentran las reformas tácitas; estas consisten en la generación de mandatos pertenecientes a la Lex Legum de conformidad y respeto de los mecanismos de reforma, es decir que son hechas por el organismo competente de conformidad con el trámite establecido; sin embargo en ellas no se deroga o se suprime de forma expresa el texto reformado, lo cual nos llevará a una indeseable confusión constitucional.

La reforma tácita se configura como una forma típica de modificación dentro del ordenamiento constitucional norteamericano, a través del sistema de las enmiendas; en ellas no se hace alusión expresa a los mandatos modificados o derogados en este orden de ideas. Caso similar se ha visto en la constitución de Weimar y nos acarreará una problemática doble dentro del sistema jurídico; en primer lugar como bien lo plantea De Vega (2007), nos lleva a una desvalorización de ley fundamental, para terminar en una indeseable pérdida del sentimiento constitucional en términos de pensadores alemanes o bien a diferenciar entre tener y vivir en una Constitución en términos aristotélicos. (Aristóteles, 2006)

Valdrá la pena, de nuestra parte, decir que las modificaciones de la Constitución deben hacerse en el caso colombiano con mención explícita de los artículos que se modifican; así el referéndum o el acto legislativo por medio del cual se modifica la Carta habrán de mencionar cuáles son los artículos que verán cambiado su contenido a través de la aplicación del mecanismo de reforma.

No obstante, la problemática del cambio material tácito a la Constitución permanecerá latente, y habrá que estar atentos para que el mismo no suceda, pues dada la característica propia del sistema colombiano de la igualdad entre la universalidad de los preceptos constitucionales, una reforma de un determinado artículo podrá afectar los contenidos de otros, lo cual, podrá derivar en una reforma tácita directa ${ }^{10}$, cuando se modifique un artículo que es remitido a otro constitucional.

Por ejemplo, los apartes propios del control de constitucionalidad del artículo 241 de la Carta Magna colombiana hacen mención a los poderes propios del estado de excepción del Presidente de la República, y si los artículos 212, 213, 214 y 215 de la Constitución manejando hipótesis, fueran modificados en forma tácita por remisión directa, serían modificados así mismo los apartes propios del artículo 241.

En igual sentido puede existir una modificación tácita indirecta, como en el caso

10 El concepto se adhiere a los demás mecanismos de alteración constitucional para completar las diversas posibilidades que existen. 
de España, "que viene a ser más notorio al existir una naturaleza particular en diferentes grados jerárquicos dentro de la misma Constitución, lo que hace que la afectación tácita, directa e indirecta pueda ser aún más compleja" (De Vega, 2007, p. 163), cuando la modificación de un artículo entrañará un cambio sustancial y una alteración a otro precepto, aunque no tenga una conexión directa. Piénsese en la relevancia en términos de interpretación de los derechos fundamentales con la modificación de un artículo propio de las garantías inherentes al ser humano (art. 94 constitucional colombiano) o en la eliminación del bloque de constitucionalidad (art. 93 constitucional colombiano)

\subsubsection{Sustitución}

En esta tensión encontramos la doctrina de la sustitución a la Constitución (DSC) o "doctrina de la inconstitucionalidad por sustitución" (DIS) según la cual determinadas reformas, al contradecir mandatos materiales implícitos en la Carta Magna y afectar gravemente los pilares fundantes del Estado Social de derecho, deben ser declaradas inexequibles $\mathrm{y}$, por lo tanto, desprovistas de valor jurídico. Se trata de un acto jurisdiccional que impide que una norma llegue a ser de rango superior.

Así las cosas, el órgano de reforma puede hacer ciertas modificaciones a la Constitución, pero al tratarse de un poder constituido, es delegado por el constituyente originario para reformar (sea modificar o enmendar), pero no para crear la Norma de Normas; si la modificación excede ese límite se trata de un acto antijurídico.

Consideramos que en el caso colombiano la doctrina de la sustitución de la Constitución ha tenido un desarrollo estable y coherente en la jurisprudencia nacional constitucional desde una génesis lingüística, pasando por la utilización de principios hasta lograr estabilización como precedente, siendo una doctrina sólida interpretativa y argumentativamente, por los métodos utilizados y el despliegue racional analítico en el estudio de los argumentos y contra argumentos dados, configurándose en una tesis garantista del Estado social de derecho sin configurarse en una contradicción del principio democrático sino en un amparo del mismo, pasando de ser un mero concepto o doctrina auxiliar a consolidarse como una institución jurídica.

Siendo el mayor reto de esta doctrina, su aplicación a un caso concreto, pues nada impide que en el futuro, el exceso de competencias se dé en la actividad de la jurisdicción, y no en el órgano de reforma, por lo tanto un juicio de sustitución a la Constitución implica amplias, detalladas y explícitas herramientas interpretativas y argumentativas que eviten la arbitrariedad y subjetividad a la hora de adoptar una decisión por parte del órgano jurisdiccional constitucional a través de su jurisprudencia.

\subsubsection{Quebrantamiento y suspensión constitucional}

Por otro lado se evidencia el fenómeno del quebrantamiento y suspensión de la 
Constitución que bien es mencionado por la propia Corte Constitucional en su sentencia de constitucionalidad C - 588 de 2009 M.P. Dr. Gabriel Eduardo Mendoza Martelo, así:

\begin{abstract}
El quebrantamiento de la Constitución, se define como la violación de prescripciones constitucionales para uno o varios casos determinados, pero a título excepcional, es decir, bajo el supuesto de que las prescripciones quebrantadas, siguen inalterables en lo demás, y, por lo tanto, no son ni suprimidas permanentemente, ni colocadas temporalmente fuera de vigor.
\end{abstract}

Según este fenómeno, el principio de generalidad característico de las normas jurídicas y, claro, de las normas constitucionales se ve envuelto en una excepción que establecerá la inaplicabilidad del precepto supremo para determinados casos o circunstancias, situación que puede ocurrir bien por una auto-ruptura" ${ }^{11}$, cuando el mismo marco constitucional establece las excepciones a la aplicabilidad del precepto, bien por una autorización a la autoruptura, cuando el marco constitucional acepta la posibilidad de una reforma que establezca la mencionada excepción o por una ruptura en alteración de los mandatos normativos constitucionales causada por el órgano de reforma.

Esta situación presenta profundos inconvenientes, pues, en primer lugar, se acusará al quebrantamiento constitucional de violar el principio de generalidad ante

1 Se entienden así ruptura y quebrantamiento constitucional como fenómenos análogos. ley y, por supuesto, atentar contra el principio de igualdad; claro, ante este hecho se han planteado posiciones de eventual defensa a favor de este fenómeno, como la necesidad de especificidad de la gran abstracción y apertura que tienen los mandatos propios de las Leyes Supremas que con el transcurso del tiempo queda en evidencia ${ }^{12}$.

Pero no debe confundirse especificidad con desacato de los mandatos supremos. Es claro que una reforma o una ley que se establece para inaplicar un mandato constitucional es un acto jurídico tendente a contradecir la Constitución misma; dicho de otra manera, un caso de ruptura o quebrantamiento constitucional tiene por esencia la naturaleza de romper ese mandato y la potencial necesidad de concreción no podría ser válida si se tienen en cuenta que las situaciones jurídicas deben respetar el derecho de igualdad de forma integral.

Por supuesto, la igualdad entraña un fundamento de la idea misma del Estado de derecho y con la misma razón del Estado social de derecho, pues nadie puede estar sobre la norma.

En este orden de ideas el quebrantamiento es una antijuridicidad que constituye una imposición de lo fáctico sobre lo jurídico, en la cual la dimensión abstracta de la igualdad es desestimada por una

12 Por supuesto puede tratarse de una razón de encubrimiento al deseo político contra la voluntad del constituyente, como de la discusión en sede de una problemática que no fue pensada al momento de la promulgación de la Norma de Normas. 
concepción concreta, y pretenderá hacerse ver como racional un desacato de los mandatos proferidos en la Carta Magna, al no someterse al mismo derecho a la igualdad en sentido de igualdad entre iguales y diferentes entre diferentes.

Así, debe considerarse que las únicas formas tolerables de ruptura constitucional del Estado social de derecho serán la au toruptura o la ruptura autorizada a través de los mecanismos de reforma, pero en ningún caso la ruptura vía modificación constitucional; entonces cualquier ruptura a la Constitución vía referéndum, acto legislativo o cualquier otro mecanismo de reforma será una acto desprovisto de competencia por parte del órgano reformador.

Como se expone en el esquema, existe la posibilidad de un trato excepcional justificado constitucionalmente en la idea misma de igualdad en sentido material, claro está, bajo los consabidos preceptos de justificación del trato discriminatorio, amparo a una población excluida, erradicación de las injusticias y proporcionalidad $^{13}$.

De forma paralela a este fenómeno se evidencia el de la suspensión constitucional, la cual:

tiene lugar cuando una o varias prescripciones son provisional-

13 Una reforma que incluye curules directas a población campesina víctima de la violencia, por ejemplo, puede ser un quebrantamiento, pero uno jurídicamente justificable, muy diferente a una reforma Ad Hoc para facilitarle a un partido mayoritario la inmunidad parlamentaria. mente puestas fuera de vigor y puede presentarse sin contrariar la Constitución, cuando se observan las prescripciones a tal efecto previstas, como en el caso de los estados de excepción; pero también de manera inconstitucional si las prescripciones legal-constitucionales son puestas fuera de vigor sin que esta suspensión se encuentre prevista (auto suspensión y autorización de la auto suspensión) en una regulación legal-constitucional, o con desprecio de un procedimiento acaso previsto para realizarla. (Corte Constitucional Colombia, 2009).

En este caso no son los hechos y las circunstancias los que generan la distinción en el marco constitucional sino los aspectos temporales, según los cuales no serán aplicados determinados preceptos constitucionales durante un periodo de tiempo.

En todo caso debe insistirse en que la suspensión constitucional podrá darse en casos de autosuspensión, cuando el poder constituyente establezca aplicaciones diferidas, incluso en el caso colombiano se encuentra una existencia de artículos transitorios, para la implementación del mismo marco constitucional, sin embargo fuera de esto cualquier aplicación de una suspensión constitucional es un acto de soberanía directo y fundacional, por lo tanto no un acto que desde un punto de vista jurídico pueda desarrollar un órgano constituido, el definir cuales leyes se aplican y cuáles no, o en qué términos una vez proferidas estas leyes van a afectar 
situaciones vigentes es una clara violación del régimen de derecho.

Dicho de otra manera, un órgano constituido, por lo tanto sometido al régimen jurídico, no puede o podría estar ajustado a la ley y a la Constitución, y definir qué leyes y que normas aplica. La concepción de la universalidad de personas naturales, jurídicas, públicas y privadas, sometidas al imperio de derecho hace que no sea discrecional de ninguno de ellos escoger que normas habrán que aplicarse y cuáles no.

Así las cosas, la suspensión constitucional vendría a ser una alteración inconstitucional, a pesar de ser proferida por los órganos autorizados para la reforma del cuerpo mismo de la Constitución, pues la reforma tiene que estar enmarcada dentro de las características propias del órgano constituido, y bien la suspensión o el quebrantamiento no originarios o no autorizados por la Constitución vienen a convertirse en actos originarios, y propios del pueblo soberano organizado como tal.

El fenómeno no es nuevo en Colombia, pues la discusión se ha dado en varias oportunidades; una es el caso de la sentencia C-574 del 2011, en la que se analiza el Acto Legislativo 02 del 2009, mediante el cual se planteó la posibilidad de penalizar el consumo de drogas; en este caso, de haber prosperado la penalización del consumo de estupefacientes se habría tratado de un claro quebrantamiento constitucional; después de todo, eran claros, evidentes y notorios los precedentes de la Corte Constitucional, como la sentencia C-221 de 1994, que habían declarado inexequible los apartes propios del Código Penal por considerar que la penalización del consumo de drogas era violatoria de derechos fundamentales.

De haber prosperado la propuesta inicial del Gobierno ${ }^{14}$ y haberse penalizado el consumo de drogas la sociedad podría verse inmersa en una clara circunstancia del quebrantamiento constitucional, donde la reforma se establece para desmontar el precedente y el fallo construido por el tribunal constitucional, en razonables (no infalibles) interpretaciones de los mandatos constitucionales.

En todo caso, no fue lo acontecido por la reforma planteada, pues bien establece que -no habrá conducción forzosa- Y, por lo tanto, es claro que no se trata de un delito; así lo entiende en forma acertada la jurisprudencia de la Corte Constitucional en su sentencia C-574 de 2011: "Sobre el trámite de este Acto Legislativo se comprueba que desde la Exposición de Motivos hasta la aprobación final de dicha reforma, se tiene en cuenta lo que se estableció en la Sentencia C-221 de 2004" que junto con estas razones y abonada la carga argumentativa que debe tener el ciudadano en una acusación de sustitución a la Constitución, considera constitucional y por lo tanto válido el acto reformatorio planteado. Dejando en evidencia que este juicio demanda el análisis de la proporcionalidad de la medida en el estudio de su idoneidad, adecuación, y proporcionalidad ${ }^{15}$.

14 Propuesta del Acto Legislativo 285 de 2009 (Cámara de Representantes), 020 de 2009 (Senado).

15 También puede verse el caso de la reforma cons- 
Es evidente que la negociación colectiva en materia laboral es un derecho irreemplazable para efectivizar la protección que la Constitución ha otorgado al derecho fundamental del trabajo. Por consiguiente, restringir el derecho a la negociación colectiva laboral en el ordenamiento jurídico, tal como sucedió con el Acto Legislativo 01 de 2005, suscita una restricción al derecho al trabajo, el cual es uno de los elementos definitorios del Estado social de derecho. Por supuesto, una aplicación coherente de la Constitución puede modular estos efectos, respetando la confianza legítima y la estabilidad de los interesados.

A título personal, para realizar una recopilación e ilustrar la reacción e interrelación entre los conceptos de sustitución, quebrantamiento, suspensión y reforma tácita se propone y expone el siguiente esquema para una retención gráfica de los fenómenos:

titucional como mecanismo para el desmonte de derechos adquiridos, como derechos laborales e incluso de quienes ejercieron sus prestaciones como empleados en régimen, para vía reforma constitucional, perder esos derechos (Salinas, 2012), este caso se acredita como un caso de ruptura constitucional, aunque, probablemente la falta de precedentes dentro de la línea jurisprudencial sólida y el lenguaje propio de esta doctrina dificultó la labor al momento de valorar e imputar una eventual inexequibilidad de la reforma.

\section{Alteraciones a la constitución mediante mecanismos formales}

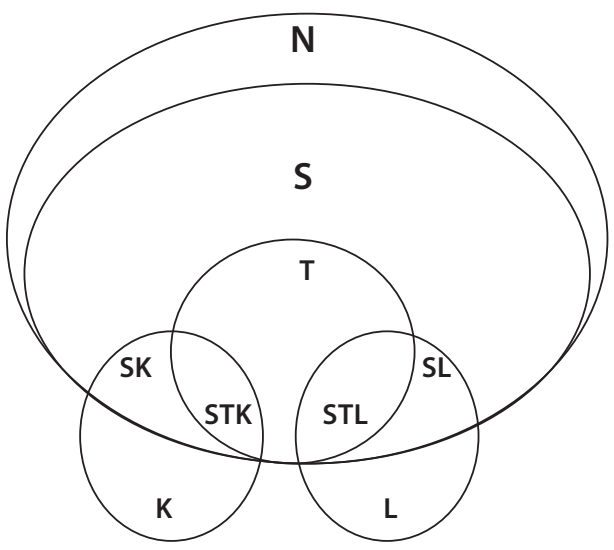

Fuente: elaboración propia

\section{Convenciones}

N: Violación a los límites competenciales del órgano de reforma.

S: Sustitución de la Constitución, afectación grave en un elemento definitorio de la Constitución.

K: Quebrantamiento, excepción introducida a las disposiciones constitucionales.

L: Suspensión, limitación temporal a las disposiciones constitucionales.

SL: Excepción temporal en elementos definitorios de la Carta.

SK: Excepción de aplicación de un elemento definitorio de la Carta.

T: Modificación tácita, consecuencia de la reforma en otra disposición constitucional. Implica una sustitución que puede ser concurrente con el quebrantamiento (STK) o la suspensión (STL)

K fuera de N: Auto-quebrantamiento reconocido en la Constitución

L fuera de N: Auto-suspensión reconocida en la Carta. 


\subsection{Alteraciones por modificaciones NO formales}

Dentro de la gama de las modificaciones no formales de la Constitución, es decir, diferentes a las realizadas por el órgano constituyente (original o derivado), se evidencian la mutación constitucional, el fraude y la elusión constitucional. En este caso la modificación a la Constitución se da por vías que implican una afectación a su eficacia, más que a su texto.

\subsubsection{Mutación constitucional: modificación no formal por excelencia}

La mutación constitucional consiste en un fenómeno, ya no propio de los órganos de poder constituyente y constituido, en tanto que ellos están autorizados para la modificación de la Constitución, sino de los operadores judiciales. Bien hablan del tema Jellinek (1991) y el mismo Hesse (2011), al sostener que una mutación modifica el contenido de las normas que contiene el texto de las mismas. Así, una mutación se configura como un hecho o una alteración que no afecta el texto sino el contenido de los mandatos constitucionales.

Sin embargo un sector considerable y sólido de la doctrina, no desestima por este simple hecho la validez de la mutación constitucional como fuente de derecho, pues bien puede ser entendida como una vía de adaptación de los preceptos y los postulados con la realidad social, así bien lo explican Müller(1989) y Carlos López Cadena. (López, 2009).

Por otro lado, la mutación constitucional también podrá derivar en un eventual caso de sustitución a la Constitución cuando el mismo implique una alteración de los elementos definitorios de la Carta Magna ya no realizando una interpretación o adaptación a la sociedad sino modificando la naturaleza de las características que le son propias a la misma (Tovar, 2012).

En el caso de la mutación constitucional puede ser entendida como una modificación a través de mecanismos no formales, la cual ha sido considerada por la doctrina, principalmente Hsü Dau $\mathrm{Lin}^{16}$, como un fenómeno que en forma clara es distinguible de la reforma, pero igualmente considerado una alteración constitucional:

Por reforma de la Constitución entiendo la modificación de los textos constitucionales producida por acciones voluntarias e intencionadas. Y por mutación de la Constitución, entiendo la modificación que deja indemne su texto sin cambiarlo formalmente que se produce por hechos que no tienen que ir acompañados por la intención, o conciencia, de tal mutación (Hsü, 1998), la cual se da por cuatro diferentes tipos: Mutación de la Constitución mediante una práctica estatal que no viola formalmente la Constitución; 2) Mutación de la Constitución mediante la imposibilidad de ejercer ciertos derechos estatuidos constitucionalmente; 3) Mutación de la Constitución mediante una práctica estatal contradictoria con la Constitución; y, 4) Mutación de la Constitución mediante su interpretación (Hsü, 1998).

16 En su milenaria lengua: 徐道鄰 
En primer lugar, por mutaciones, dadas las prácticas políticas que no están en oposición directa con la Constitución, y que configuran más bien un complemento a los vacíos y abstracciones propios de la Lex Legum. En este caso debe considerarse que es muy probable que no se trate de una reforma constitucional en estricto sino de una operación común de concreción de preceptos abstractos de orden constitucional.

En segundo lugar, se evidencian mutaciones en prácticas con abierta oposición a esos mandatos constitucionales, donde la realidad pragmática o fáctica y los preceptos normativos se encuentran en absoluta oposición, lo que hace que no pueda considerarse esto como una verdadera y auténtica mutación de constitucionalidad sino como un desacato, por lo tanto, una inconstitucionalidad de las mismas normas y conductas.

Por otro lado, se evidencia la mutación por desuetudo o desuso de los mismos mandamientos constitucionales; en este caso existen los derechos y competencias, pero aun con la pretensión de realizarse, hay situaciones reales que impiden su materialización, pues se encuentra frente a un acto de ineficacia; por lo tanto, esta tercera forma de mutación constitucional también se considera como inexistente.

Como cuarta fórmula se hallan las mutaciones producidas por los cambios interpretativos lo que genera que los preceptos obtengan un concepto distinto de aquel que se había planteado en sus inicios; así, de las modificaciones no formales, bien sean procedentes de órganos no formales, generaciones normativas, interpretativas o propias de la naturaleza real, será tenida en cuenta como única mutación ${ }^{17}$ la dada por las interpretaciones en el cambio entre disposiciones y normas constitucionales.

Este procedimiento puede desarrollar y adaptar la normativa, pero también las propias cortes constitucionales pueden usurpar funciones, poderes o competencias de las que en estrictos términos constitucionales carecen, ellas también pueden autoquebrantar con sus decisiones la Constitución, lo cual dependerá de evaluar la decisión concreta. Casos como la evolución del bloque de constitucionalidad (93 constitucional) son visiblemente más legítimos que sentencias realizadas en violación del propio precedente para favorecer intereses políticos como es el caso de la sentencia SU 424 de 2016 en Colombia que hace más laxos los criterios de pérdida de investidura y debilita la lucha contra la corrupción.

En todo caso, no se consideran como propias de la mutación constitucional las regulaciones, en el caso colombiano, de leyes estatutarias o decretos reglamentarios que pudieran contradecir esos mandatos, pues este mecanismo subrepticio de reforma no vendrá a ser más que un acto inconstitucional (De Vega, 2007).

Podría concluirse entonces que en los casos de mutación a la Constitución se darán vías interpretativas las cuales, bien,

17 De manera auténtica y no en forma nominal. 
podrán ser por un cambio histórico en la semántica o derivado de nuevas relaciones sociales, hechos que permiten las relecturas de los marcos constitucionales; así, la diferencia entre ámbito normativo y programa normativo (López, 2009) se convertirá en una modificación no formal de la carta constitucional.

Sin embargo, se somete a consideración que la reforma y por supuesto la modificación de los pilares estructurales de la Carta Magna no pueden ser modificados vía mutación constitucional; así se comparte lo dicho por López (2009):

\begin{abstract}
En el vigente sistema establecido por la Constitución de 1991, solo es admisible un concepto de mutación de los derechos que actúe única y exclusivamente dentro de los límites constitucionales y que por tanto respete los pilares fundamentales del Estado constitucional (subrayado fuera del original).
\end{abstract}

\subsubsection{Costumbres y convenciones constitucionales}

En algunos casos, como en la doctrina francesa o en la inglesa, se hablaba de la costumbre constitucional como forma uniforme de identificación de la Constitución, asociada en algunos aspectos con la misma mutación. No debe referirse por supuesto a las prácticas ilegales e inconstitucionales, pues estos son simples actos de deshonestidad y no una ejecución dentro de la norma, pues bien se contradicen los preceptos propios del orden normativo en el cual existen no solo un elemento material, es decir la actuación reiterada sino un elemento espiritual, la famosa optio iuris, en la cual se actúa bajo el convencimiento de estar de acuerdo al derecho. Las prácticas clientelistas no encuadrarían en estas costumbres, pues su actor siente estar por fuera de los parámetros del derecho, incluso si el mismo quiere justificarlos por otros medios $u$ otras necesidades.

Así, el primer inconveniente es que se evidencia en forma directa una costumbre contralegem, pues solo aquello que está fuera de lo explícito en la Constitución sería regulable o interpretable, lo que genera que el fenómeno de la costumbre, a todas luces, sea inaceptable; por otro lado, no existe autoridad ni espacio externo que permita regular y certificar la existencia de esta costumbre.

Lo anterior dirige a un tercer contra argumento de las costumbres constitucionales, pues no debe pasar inadvertido que tratándose de marcos constitucionales están, en esencia, dirigidos a la actividad pública, y un funcionario debe hacer solo aquello que le está mandado, a diferencia de los particulares que pueden hacer todo lo que no esté prohibido; por lo tanto, una costumbre fuera de lo normado no puede ser considerada como una actuación que respete los marcos constitucionales.

Como forma particular, dentro de las formas y costumbres de las alteraciones constitucionales, se ha hablado en última medida de las convenciones constitucionales; sin embargo, estas configuran más un hábito de la política que un marco constitucional, pues se caracterizan con 
precisión por no tener sanción frente a su incumplimiento; así, la única modificación que podría ser aceptable, claro en un gran campo de estudio hacia el futuro, será la mutación vía interpretación, cuando se compaginan los ámbitos normativos con los programas normativos, lo que genera un dinamismo y un empalme con la realidad social de los marcos constitucionales (Müller, 1989).

\subsubsection{La elusión constitucional}

En el marco de nuestro Estado social de derecho, la Constitución Política está investida de una supremacía normativa que se traduce en que las normas inferiores que la contravengan deberán ser excluidas del sistema jurídico. Pese a esto, en nuestro país se han ideado formas de manipulación constitucional para permitir que normas, siendo más precisos, decretos administrativos, regulen aspectos que de forma obligatoria debieran estar contenidos en una ley, promoviendo burlas y elusión de esta manera al control de constitucionalidad establecido para brindar garantías de vigilancia a los ciudadanos.

En el caso colombiano el fenómeno fue visible notoriamente antes de la entrada del nuevo procedimiento contencioso administrativo Ley 1437 de 2011, el cual ha hecho más expeditas las demandas de nulidad contra actos administrativos y ha disminuido la mora judicial; igualmente las decisiones de la jurisdicción administrativa han sido más responsables con la procedencia de las medidas cautelares de suspensión provisional del acto. Esto no niega en todo caso que el fenómeno se haya dado.

Estas políticas de evasión constitucional traen efectos adversos, pues en muchas ocasiones se realizan con el fin de privilegiar a sectores específicos de la población para reversar derechos e incluso para modificar la Constitución vía acto administrativo, otorgándose atribuciones que no le corresponde a una rama del poder público cuya función está muy al margen de las nuevas facultades autorizadas $^{18}$.

Lo que se pretende es, entonces, mimetizar (Quinche, 2009) normas para que aparenten ser válidas y ajustadas a derecho, pero que en realidad son en alguna forma violatorias de la Constitución, bien porque contengan un mandato que vaya de manera literal en contra de una norma constitucional, o porque desarrollen una temática con reserva de ley; situaciones que al estar por fuera del alcance del control constitucional ${ }^{19}$ continúan con plena vigencia en el ordenamiento jurídico, pese a desconocer el principio de supremacía constitucional.

18 Es el caso, por ejemplo, de normas transitorias contenidas en actos legislativos en los que se le otorgan al Presidente de la República facultades extraordinarias para modificar normas contentivas de materias con reserva de la Constitución y de la ley, sin perjuicio de las expresas prohibiciones que al respecto se establezcan

19 Es importante precisar que el hecho de ser decretos de carácter administrativo no los exime en forma absoluta de control constitucional, pero la competencia para su estudio estará en cabeza del Consejo de Estado y no de la Corte Constitucional. 
Aunado a lo anterior, debe sostenerse que el irrespeto a la voluntad de la mayoría o a los espacios de las minorías se asoma en América Latina en la forma de intentos de golpes de Estado; de escaladas de autoritarismo oficialista; de relativismo o disfraz constitucional de actos antidemocráticos abiertos y plenos y de elusiones, fraudes y otros mecanismos de evasión o de destrucción de la Constitución como contrato social y como carta de navegación (Nino, 2002).

\section{Alteraciones a la constitucion mediante mecanismos no formales}

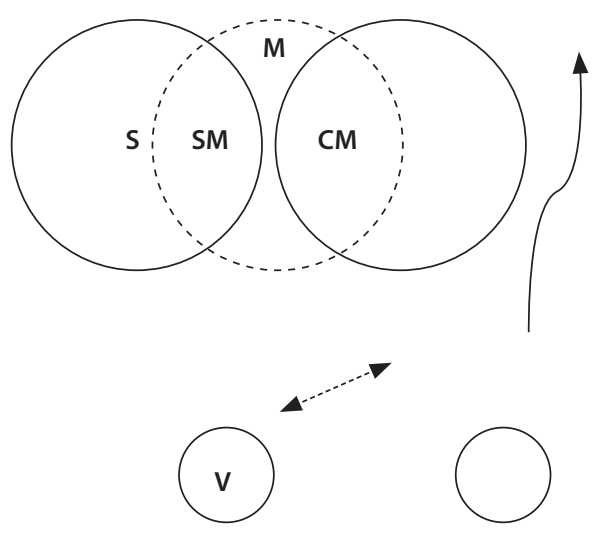

Fuente: elaboración propia

\section{C: Carta Magna}

S: $\quad$ Sustitución de la Constitución, afectación grave en un elemento definitorio de la Carta Magna.

M: Mutación. Modificación de los contenidos sin afectación de las disposiciones, en este sentido se da por una actividad que no es de normas positivas, como puede serlo la interpretación jurisdiccional.

V: Convención. Conducta no positivizada que se considera inconstitucional o extrajurídico.
U: Elusión. Norma (de inferior jerarquía) destinada a no cumplir los mandatos constitucionales, inconstitucional.

SM: Sustitución por mutación. Sin afectación de las disposiciones, cambio de contenido en un elemento esencial y definitorio.

Se puede ver cómo la Constitución (CN) es excluyente con los actos de sustitución(S); en ocasiones puede ser concurrente con la mutación (M) cuando se da la adaptación legítima de la norma al contexto; puede estar por fuera de la Constitución cuando la modifica gravemente y puede incluso ser concurrente con una Sustitución (SM). Las costumbres (V) pueden parecer, pero no son normativas ni se conectan a la Constitución; la elución (U) desacata el imperativo que debería conectarse. Sin embargo, dentro de estas categorías, se encuentran varios mecanismos o formas de alteración a la estabilidad de la Carta Magna, es decir, que existen diferentes fenómenos según los cuales la integralidad original va a verse modificada. Se refiere de manera esencial a las modificaciones formales y a las modificaciones informales.

El siguiente grupo une la mutación, la reforma tácita, el quebrantamiento y la suspensión; se quitan los límites competenciales porque sale el análisis de lo solo normativo, mostrándose finalmente el fraude a la Constitución: 


\section{Alteraciones mediante mecanismos formales y no formales}

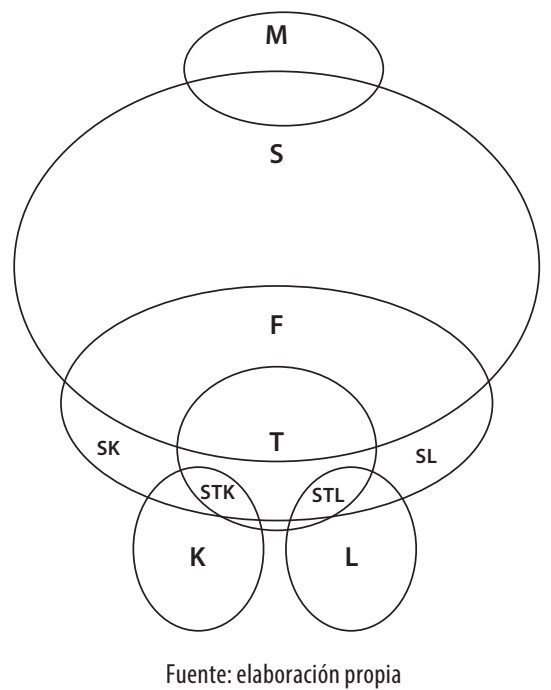

S: $\quad$ Sustitución de la Constitución, afectación grave en un elemento definitorio de la Carta Magna.

M: $\quad$ Mutación. Modificación de los contenidos sin afectación de las disposiciones.

K: Quebrantamiento, excepción introducida a las disposiciones constitucionales.

L: Suspensión, limitación temporal a las disposiciones constitucionales.

SL: Excepción temporal en elementos definitorios de la Carta.

SK: Excepción de aplicación de un elemento definitorio de la Carta.

T: $\quad$ Modificación tácita, consecuencia de la reforma en otra disposición constitucional. Implica una sustitución que puede ser concurrente con el quebrantamiento (STK) o la suspensión (STL)

K fuera de S (y de N): Auto-quebrantamiento reconocido en la Constitución.

L fuera de S (y de N): Auto-suspensión reconocida en la Carta.

F: $\quad$ Fraude a la Constitución.

\section{CONCLUSIONES}

Se ha evidenciado cómo la instrumentalización de los mecanismos de reforma puede llegar a afectar los elementos esenciales de la Constitución, configurándose una violación a los límites competenciales del órgano de reforma.

Si bien es notoria la necesidad de permitir la adaptación de la Constitución a las exigencias del momento, no menos cierto es que estos mecanismos deben ser usados para su fin legítimo; adaptar no es destruir, después de todo.

La utilización de esquemas lógicos nos permitió exponer la conexión entre las diversas alteraciones formales (o derivadas del uso de mecanismos formales), cuando concurren o incluso se interrelacionan y cuando no dichas alteraciones.

Caso diferente a las alteraciones derivadas del uso de mecanismos no formales, como la mutación o la elusión constitucional, estas por su informalidad misma no podrían ser esquematizadas en un sistema lógico-formal.

Por último, debe insistirse en que las afectaciones a los límites materiales implícitos de estas alteraciones constitucionales deben ser consideradas antijurídicas, lo cual ha sido desarrollado en forma profunda y acertada por la Corte Constitucional colombiana en la doctrina de la inconstitucionalidad por Sustitución. El reto será en el futuro establecer la sanción jurídica a las demás formas de alteraciones para garantizar la estabilidad y el respeto de 
la Constitución y que esta pueda desplegar su pretensión de dignificación del hombre.

Se hace necesario dejar al final la cita directa de George Orwell, de su obra, Rebelión en la granja, la cual queda no solo a manera de reflexión, sino de invitación para el ejercicio de una democracia participativa responsable y que vincule a todos los sectores de la sociedad:

—-La vista me está fallando - dijo ella finalmente- - Ni aun cuando era joven podía leer lo que estaba ahí escrito. Pero me parece que esa pared está cambiada. ¿Están igual que antes los siete mandamientos, Benjamín?

Por primera vez Benjamín consintió en romper la costumbre y leyó lo que estaba escrito en el muro. Alli no había nada excepto un solo Mandamiento. Éste decía:

"Todos los animales son iguales, pero algunos animales son más iguales que otros".

George Orwell.

Rebelión de la granja.

\section{REFERENCIAS BIBLIOGRÁFICAS}

Aristóteles. (2006). La Política. Madrid; Istmo.

Bryce, J. (1988). Constituciones flexibles y rígidas. Madrid; Centro de Estudios Constitucionales.

Carré De Malberg. R. (1998). Teoría general del Estado. México; Fondo de Cultura Económica.

Corte Constitucional. Sentencia SU-1122 de 2001. M.P. Eduardo Montealegre Lynett. Bogotá, 25 de octubre de 2001.
Corte Constitucional. Sentencia C-551, M. P. Eduardo Montealegre Lynett, Bogotá, 09 de julio de 2003.

Corte Constitucional. Sentencia C-588, M.P. Gabriel Eduardo Mendoza Martelo, Bogotá, 27 de agosto de 2009.

Corte Constitucional. Sentencia C-397, M.P. Juan Carlos Henao Pérez, Bogotá, 25 de mayo de 2010.

Corte Constitucional, Sentencia C-141, M.P. Humberto Antonio Sierra Porto, Bogotá, 26 de febrero de 2010.

Corte Constitucional. Sentencia C-574 de 2011, M.P. Juan Carlos Henao Pérez, Bogotá, 22 de julio de 2011.

Corte Constitucional. Sentencia C-170 M.P. Jorge Iván Palacio. Bogotá. 7 de marzo 2012.

Corte Constitucional. Sentencia C- 249 M.P. Juan Carlos Henao Pérez. Bogotá 29 de marzo de 2012.

Corte Constitucional. Sentencia C-336 M.P. Mauricio González Cuervo. Bogotá. 13 de junio de 2013.

Falcón y Tella, M. (1994) Concepto y fundamento de la validez del derecho. Madrid: Universidad Complutense de Madrid.

Ferreyra, R. (2007). Reforma constitucional y control de constitucionalidad. Buenos Aires: Ediar.

Guglielmi, G. (2008) La non constitution francaise. Extraído de http://www.guglielmi.fr/spip. php?articlel41 el 15 de noviembre 2008.

Hart, H. (1983) Positivism and the separation of law and morals. Oxford. Oxford Clarendon Press.

Henao, J. (2013). Diálogos constitucionales de Colombia con el Mundo- VII Encuentro de la Jurisdicción Constitucional. Bogotá D. C: Universidad Externado de Colombia. 
Hesse, K. (2011). Escritos de derecho constitucional. Madrid: Centro de Estudios Constitucionales.

Higuera, D. (2009). El ejercicio del órgano de control de constitucionalidad en Francia y en Colombia. Tunja. Revista Principia Iuris (11), p. 137 . 159. Universidad Santo Tomas, Seccional Tunja. Centro de Investigaciones Jurídicas y Socio-jurídicas.

Higuera, D. (2009). Estudio integrado de la legitimidad en la corte constitucional colombiana. Tunja. Revista Principia Iuris (12), p. 91. Universidad Santo Tomas, Seccional Tunja. Centro de Investigaciones Jurídicas y Socio-jurídicas.

Higuera, D. (2012). Bloque de constitucionalidad en Colombia: una propuesta de rigor y garantía. Madrid : Editorial académica española.

Higuera, D. (2015-A). Le contrôle de constitutionnalité en France et en Colombie. En France. Editions Universitaires Européennes. ISBN: 978-38416-6469-3. V 500. P. 180. 2015.

Higuera, D. (2015-B). Protección de la dignidad humana: Control de constitucionalidad e implementación de mecanismos internacionales. Bogotá: Editorial Ibáñez. 2015.

Higuera, D. (2015-C). Tipologías de derechos, ¿Una variante en la tutela judicial efectiva?: Un análisis desde la ineficacia de la acción de cumplimiento para los derechos sociales. Bogotá: Revista Via Iuris 20 p. 13-28. Fundación Universitaria Los Libertadores.

Higuera, D. (2016). Análisis dinámico de la línea jurisprudencial respecto de la sustitución de la Constitución. Tunja. Revista Principia Iuris 26. p. 213-242. Universidad Santo Tomás, Seccional Tunja. Centro de Investigaciones Jurídicas y Socio Jurídicas.

Hsü, D. (1998). Mutación de la Constitución. Traducción de LUCAS VERDÚ Pablo y FÖRSTER
Carlos. San Sebastián. Instituto Vasco de Administración Pública.

Jellinek, G. (1991). Reforma y mutación de la constitución. Madrid: Centro de Estudios Constitucionales.

Julio, A. (1997). La teoría de los derechos públicos subjetivos en la orba de Georg Jellinek. Bogotá: Universidad Externado de Colombia.

Kelsen, H. (1962). Teoría pura del derecho. París:Dalloz.

Kelsen, H. (1988) Teoría general del estado. México D. F: Coyoacán.

López, C. (2009). Aproximación a un concepto normativo de mutación de los derechos, Bogotá: Universidad Externado de Colombia.

López, D. (2006). El derecho de los jueces. Bogotá: Editorial Legis. Segunda edición

López, D. (2002). Manual de interpretación constitucional. Bogotá: Consejo Superior de la Judicatura-Escuela Judicial Rodrigo Lara Bonilla.

Loewenstein, K. (1982). Teoría de la Constitución. Barcelona. Editorial Ariel.

Múller, F. (1989). Tesis acerca de la estructura de las normas jurídicas, Trad. Luís Villacorta, en Revista Española de Derecho Constitucional, (27), p. 111-126.

Nino, C. (2002). Fundamentos del Derecho Constitucional: Análisis filosófico, jurídico y politológico de la práctica constitucional. Buenos Aires. Astrea.

Orwell, G. (1945). Rebelión en la Granja. Londres: Editorial Destino.

Ost, F. (1987). Essai de définition et de caractérisation de la validité juridique, en «Droit et Pouvoir». T. 1. Bruxelles: Story- Scientia.

Ost, F, Van De Kerchove, M. (2001). Elementos para una Teoría critica del Derecho. Bogotá D. C: Editorial Unibiblos. 
Pace, A.E Varela, J. (1995). La rigidez de las constituciones escritas. Madrid: Centro de Estudios Constitucionales.

Pérez, J. (1998). Los límites jurídicos al soberano. Madrid : Edit. Tecnos.

Pierre-Caps, S. \& Constantinesco, V. (2006).Droit constitutionnel. París : Thémis droit.

Posner, R. (2011). Cómo deciden los jueces. Madrid: Ediciones Jurídicas y Sociales.

Prieto, Luis. (1997).Constitucionalismo y Positivismo. México:Fontamara.

Quinche, M. (2009). La elusión constitucional, una política de evasión del control constitucional en Colombia. Bogotá: Editorial Universidad del Rosario.

Quinche, M E Urrego, F. (2008). Los decretos en el sistema normativo colombiano -Una política estatal de invención normativa. Bogotá. Vniversitas. UCLS. $N_{\circ}$ 116: 53-83.

Rigaux, M. (1985). La theorie des limites materielles a l'exercice de la fonction constituante. Bruxelles:Lacier Ed.

Ross, A. (1991). Sobre la auto referencia y un difícil problema de derecho constitucional, en El concepto de validez y otros ensayos. México: Edit. Fontamara.

Rousseau, J. (1990). El contrato social. Madrid: Alianza Editorial.

Salinas, M. (2012). La reforma constitucional como mecanismo para reversar derechos adquiridos. Bogotá: Concurso Octavio Arizmendi Posada, Universidad de la Sabana.

Scarciglia, R. (2006). Introduzione al dirittopubblicocomparato. Bolonia. IlMulino.

Schimitt, C. (1983). La defensa de la Constitución. Madrid. Tecnos.
Schmitt, C. (1982). Teoría de la Constitución. Madrid: Alianza editorial.

Sieyes, E. (1987). ¿Quées el tercer Estado? Barcelona: Ediciones Orbis S.A. Introducción. Traducido y notas: Francisco Ayala.

Smend, R. (1985). Constitución y derecho constitucional. Madrid: Centro de Estudios Constitucionales.

Ragone, S. (2012). El control judicial de la reforma constitucional. Aspectos teóricos y comparativos. México. Editorial Porrúa.

Ramírez, G. (2003), los límites a la reforma constitucional y las garantías-límites del poder constituyente: los derechos fundamentales como paradigma. Bogotá: Universidad Externado de Colombia.

Ramírez, G. (2005) Límites de la reforma constitucional en Colombia: El concepto de Constitución como fundamento de la restricción. Bogotá: Universidad Externado de Colombia.

Ramírez, G. (2008) Reformas a la Constitución de 1991 y su control de constitucionalidad: entre democracia y demagogia. Bogotá. Revista de Derecho del Estado, $N_{0}$ 21. Universidad Externado de Colombia.

Tobo, J. (2006). La Corte Constitucional y el control de constitucionalidad en Colombia. Bogotá: Editorial Ibáñez.

Tovar, F. (2012). La teoría de la sustitución: cun caso de mutación constitucional? Principia Iuris, (17). p. 157 - 173. Universidad Santo Tomás, Seccional Tunja.

De Vega, P. (1998). La ciencia del derecho durante el siglo XX. México: Universidad Nacional.

De Vega, P. (2007).La reforma constitucional y la problemática del poder constituyente. Madrid: Tecnos. 